\title{
DESIGNING A SCRUBBER FOR MAINTENANCE
}

\author{
M. E. Mahlmeister \\ E. S. Baron \\ New York State Electric \& Gas Corporation \\ P.O. Box 5224 \\ Corporate Drive - Kirkwood Industrial Park \\ Binghamton, New York 13902-5224 \\ J. Watts \\ U. S. Department of Energy, P.E.T.C. \\ P.O. Box 10940 \\ Wallace Road, Building 920L, Room 108 \\ Pittsburgh, Pennsylvania 15236
}

\begin{abstract}
Under Round 4 of the U.S. Department of Energy's (DOE) Clean Coal Technology program, New York State Electric \& Gas Corporation (NYSEG), in partnership with Saarberg-HolterUmwelttechnik (SHU), Consolidation Coal Company and Stebbins Engineering and Manufacturing Company, has retrofitted a formic acid enhanced forced oxidation wet limestone scrubber on Units 1 and 2 at the Milliken Steam Electric Station. Units 1 and 2 are 1950s vintage Combustion Engineering tangentially fired pulverized coal units, which are rated at nominal $150 \mathrm{MW}$ each and operate in balanced draft mode. The Flue Gas Desulfurization (FGD) system for Unit 2 was placed into operation in January 1995 and the Unit 1 system in June 1995.

The project incorporates several unique aspects: low $\mathrm{pH}$ operation; a ceramic tile-lined cocurrent/countercurrent, split module absorber; a wet stack supported on the roof of the FGD building; and closed loop, zero liquid discharge operation that produces commercial grade gypsum and calcium chloride brine. The project objectives include $98 \% \mathrm{SO}_{2}$ removal efficiency while burning high sulfur coal, the production of marketable byproducts to minimize solid waste disposal, zero wastewater discharge, space-saving design, and minimization of maintenance requirements of a wet scrubber.
\end{abstract}


The paper provides a brief overview of the project scrubber design relating to maintenance considerations. A discussion of the early results of the maintenance history is also provided. Repair techniques that have been developed and tested for ceramic tile lined modules are included.

\section{Introduction}

The Milliken Clean Coal Demonstration Project is one of nine projects selected for funding in Round 4 of the U.S. DOE's Clean Coal Demonstration Program. The project provides fullscale demonstration of a combination of innovative emission-reducing technologies and plant upgrades for the control of sulfur dioxide $\left(\mathrm{SO}_{2}\right)$ and nitrogen oxides $\left(\mathrm{NO}_{\mathrm{x}}\right)$ emissions from a coal-fired steam generator without a significant loss of station efficiency.

The project's sponsor is New York State Electric and Gas Corporation (NYSEG). Project team members include CONSOL Inc., Saarberg-Holter-Umwelttechnik (SHU), NALCO Fuel Tech, Stebbins Engineering and Manufacturing Co., DHR Technologies, Inc. and ABB Air Preheater. Project cofunders include DOE, NYSEG, CONSOL, Electric Power Research Institute (EPRI), New York State Electric Energy Research and Development Authority and Empire State Electric Energy Research Corporation. Parsons Power Group is the Architect/Engineer and the Construction Manager for the Flue Gas Desulfurization (FGD) portion of the project.

The overall project goals are:

- $98 \% \mathrm{SO}_{2}$ removal using limestone while burning high sulfur coal.

- Minimization of solid wastes by producing marketable by-products including commercial grade gypsum, calcium chloride, and fly ash.

- Zero wastewater discharge.

- Maintenance of station efficiency by using a high-efficiency heat-pipe air heater system and a low-power-consuming scrubber system.

- Minimization of wet scrubber maintenance.

The host site for the demonstration project is NYSEG's Milliken Station, located in Lansing, New York. Milliken Station has two Combustion Engineering 150-MWe pulverized coalfired units built in the 1950s. 


\section{Scrubber Process Overview}

The SHU process (Figure 1) is the only developed wet-limestone FGD process designed specifically to employ the combined benefits of low-pH operation, formic acid enhancement, single-loop cocurrent/countercurrent absorption, and in situ forced oxidation. In the SHU process, the flue gas is scrubbed with a limestone solution in a cocurrent/countercurrent absorber vessel.

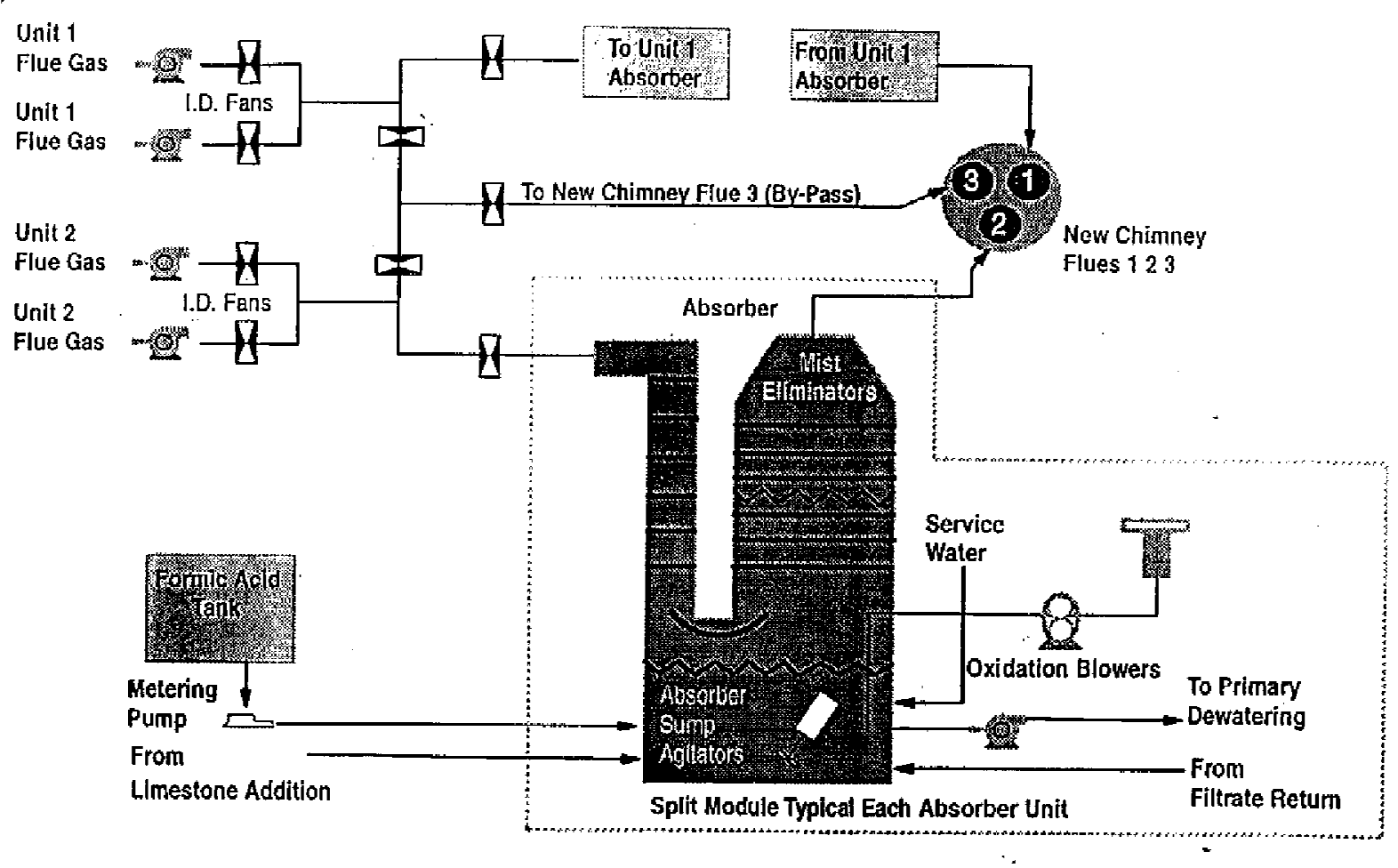

Figure 1

Simplified SHU Flow Diagram

The scrubber liquor is maintained at a low $\mathrm{pH}$ by adding formic acid, which acts as a buffer, to the absorber. Formic acid addition enhances the process in several ways, including better $\mathrm{SO}_{2}$ removal efficiency with limestone, lower limestone reagent consumption, lower blowdown rate, freedom from scaling and plugging, higher availability, lower maintenance, production of wallboard grade gypsum by-product, and improved energy efficiency compared to conventional FGD technologies.

With operation at lower $\mathrm{pH}$, the limestone reagent dissolves more quickly. This means that less limestone is needed, the limestone doesn't have to be ground as finely, and there is less limestone contamination of the gypsum by-product. Operation at lower $\mathrm{pH}$ results in more efficient oxidation of the bisulfite reaction product to bisulfate. Less excess air is needed for the oxidation reaction, and the gypsum crystals created are larger and more easily dewatered. 
Formic acid buffering improves $\mathrm{SO}_{2}$ removal efficiency. Slurry recirculation rates are reduced, saving both capital cost and energy. Buffering provides excellent stability and ease of operation during load changes and transients. The process can tolerate higher chloride concentrations (up to 70,000 ppm), reducing the amount of wastewater that must be processed. Finally, the potential for scaling of absorber internals is eliminated, resulting in reduced maintenance costs and improved availability.

The FGD process has been installed on both Units 1 and 2 with common auxiliary equipment. A single split absorber is used. This innovation features an absorber vessel divided into two sections to provide a separate absorber module for each unit. The design allows for more flexibility in power plant operations than does a single absorber while saving space on site and capital cost compared to two separate absorber vessels. The absorber shell construction is concrete, with an integral, cast in place ceramic tile liner. The tile has superior abrasion and corrosion resistance compared to rubber and alloy linings and is expected to last the life of the plant. In addition, the concrete/tile system is easily installed at existing sites where space for construction is at a premium, making it ideal for retrofit applications.

The FGD absorber modules contain no internal packing material. The spray nozzles are designed to create droplet sizes small enough to provide sufficient surface area without the use of packing in the absorber. Therefore, no maintenance is associated with packing in the SHU process.

The absorbers use two-stage mist eliminators furnished by Munters. Whereas model DV210 is used for the first stage in both absorber modules, the modules use two different secondstage designs. One absorber uses model DV-2130 and the other uses model T271. Model T271 is the vertical flow type tested by EPRI and commonly found in U.S. applications. Model DV-2130 is the Munters-Euroform V-shaped module design commonly used in European installations. The project will provide a side-by-side comparison of the two designs.

The design incorporates a new chimney erected on the roof of the FGD building, directly over the absorber vessels. Each absorber module discharges directly into a dedicated fiberglass (FRP) flue. The two FRP flues, provided by AN-COR Industrial Plastics, along with a common steel start-up by-pass flue, are enclosed within a 40-ft diameter steel chimney. This design saves space on site and eliminates the need for absorber outlet isolation dampers and extensive outlet ductwork, which are typically high maintenance items.

\section{Limestone Preparation and Addition}

Limestone is delivered to the station by truck. Space is provided for a 180-day inventory. The stone is reclaimed by front-end loader and transferred by belt conveyor to two 24-hour surge bins in the FGD building. The limestone is ground and slurried with clarified water (recycled process liquor) in conventional closed-circuit, horizontal, ball mill, wet grinding systems provided by Fuller. The $25 \%$ solids product is transferred by gravity to either of two 12-hour fresh slurry feed tanks. Redundant, continuous-loop piping systems transfer the 
product slurry to the absorbers from the fresh slurry feed tanks. Two grinding systems are provided, each with a capacity of $24 \mathrm{tph}$. One mill, operating 12 hours per day can support the process needs of both units. Each system is provided with two sets of classifiers. This allows the production of slurry with two different particle size distributions, $90 \%$ passing through 170 mesh and 90\% passing through 325 mesh. The coarser grind is used during normal operation with formic acid. Utilizing a coarser grind reduces the maintenance requirements for the grinding equipment.

\section{Gypsum Dewatering}

A bleed stream of scrubber slurry is processed for recovery of high quality by-product gypsum and calcium chloride brine. Water is recovered and recycled back to the process. There is zero wastewater discharge from the process. The gypsum is dewatered to $8 \%$ surface moisture for delivery to customers.

In the dewatering system a bleed stream containing by-product gypsum solids is withdrawn from each absorber module by bleed pumps. The bleed streams are fed to the primary hydroclones where the gypsum solids are concentrated to over $25 \mathrm{wt} \%$. The underflow from the primary hydroclones discharges to the centrifuge feed tanks. The overflow discharges to the secondary hydroclone feed tanks. Two primary hydroclone assemblies are provided by Warman. Each assembly can process the bleed from either or both absorber modules. In normal operation, the bleed from both absorbers is processed through one hydrocyclone assembly and the second assembly is a spare.

The gypsum solids from the primary hydrocyclone underflow are concentrated to 92 wt $\%$ solids by Krauss-Maffei vertical basket centrifuges. Four centrifuges are provided, of which three operate and one is a spare at maximum design conditions. The centrifuges are fed from either of two centrifuge feed tanks through continuously circulating feed loops. The rubberlined centrifuges are batch operated and incorporate a washing step designed to achieve a residual chloride concentration of less than $100 \mathrm{ppm}$. The gypsum solids are transferred by belt conveyor to an on-site storage building. Gypsum in the 4,000 ton capacity storage building is reclaimed by front-end loader and trucked from the site.

A portion of the overflow from the primary hydroclones is processed by the secondary hydroclones to a less than $3 \mathrm{wt} \%$ solids liquor. The product is used as clarified water for limestone preparation, system flushing, and blowdown to the FGD wastewater treatment system. The underflow from the secondary hydrocyclone and the balance of the primary hydrocyclone overflow are returned to the absorbers via the filtrate tanks. Two secondary hydrocyclone assemblies are provided by Warman.

\section{Design Considerations}

Design for maintenance is an important part of the DOE Milliken FGD project. As with any pollution control device that is added to a utility steam generator, the main objective is to 
provide the required emission control process with minimal impact on unit profitability. The pollution control device should not add substantial amounts of down time and operating expense to the generating unit. The goals of the project were to minimize the costs associated with building and operating a FGD plant. The FGD plant incorporates many innovations in the process, design, and materials to accomplish these goals. The impact that the materials and design would have on maintenance was reviewed thoroughly.

Early in the layout of the FGD it was determined that access for maintenance was of utmost importance. The layout was reviewed by maintenance personnel for suggestions that would improve the access to all equipment. A three dimensional computerized design model aided in this phase of the project by providing immediate feedback on various layouts and the space between equipment. The model also allowed direct layout of several areas of the FGD by plant personnel until they were satisfied that it incorporated enough access. All larger equipment had monorails installed above them to aid in removing casings, impellers, gearboxes etc. The access for forklifts into and around equipment was incorporated. Chases for lifting items to higher floors were arranged so that they would be near overhead doors for easy access.

The access around and into the absorber module is important in reducing maintenance costs. The layout of the recycle pumps, agitators, and bleed pumps allows room to maintain or repair any of the equipment. The module sumps are easily accessible as are the various spray levels and the mist eliminators. These areas contain access doors which allow the entrance or exit of all major components in the largest size possible thereby minimizing the time needed to repair internals. The personnel access doors provide easy access to spray levels and passage of required scaffolding. The module has necessary permanent support required for easy installation of scaffolding to allow maintenance. The module sump has a large door which allows the sump to be cleaned quickly and efficiently. The door is large enough to pass of electric genie lifts which allow access to turning vanes and upper sump areas for inspection of the tile.

Maintenance considerations greatly influenced the design of systems and purchase of equipment. Materials that went into the construction of the FGD systems and equipment were reviewed to determine longevity or the ease of their repair. New materials not widely used in other scrubbing applications were used. The maintenance cycles of equipment were reviewed between competing bids to determine least costs. The ease of maintaining equipment was also an evaluation factor in determining purchases.

\section{Absorber Modules}

Similar to the operating requirements of other wet limestone FGD systems, the SHU process utilizes a scrubber slurry that contains abrasive materials. In addition, the chloride level in the SHU process is not as limited as other wet systems. The design operating chloride level is $40,000 \mathrm{ppm}$ with a design maximum of 70,000 ppm. The current design philosophy of limiting the number of absorber vessels to lower capital costs has emphasized the need to select a construction material that is both long lasting and easily maintained. Materials of 
construction of absorber modules are one of the major maintenance costs associated with wet scrubbers.

A major feature of the Milliken DOE demonstration project is the use of a Stebbins tile lined absorber module. Ceramic tiles are widely used in the pulp and paper industry for chemical and abrasion resistance. Ceramic tiles have also been used on a limited basis in retrofit applications for utility scrubbers, but never with the design and operating chloride level associated with the Milliken scrubber. Laboratory testing of ceramic tiles in a simulated FGD environment confirmed the applicability to our process.

By utilizing Stebbins tile, many of the variables associated with the installation of other lining systems were avoided. The likelihood of a module causing a scrubber outage is reduced, since repair procedures can be completed on line. Results obtained from a test module installed at another NYSEG FGD site indicate the structure is self-healing. Holes and cracks will tend to seal themselves before a repair is required. Operation of the Milliken scrubber has also shown the self-healing capabilities of the tile system. If maintenance of the tile is required, it is less costly than other construction materials.

\section{Absorber Vessel Internals}

The use of rubber lined material in the absorber module was held to a minimum. Rubber was used only in those instances when structural requirements dictated the use of steel for strength. In these applications the use of an alloy would have been extremely expensive. All of the recycle spray headers, except the headers which are in a high temperature region, are made of fiberglass with an internal and external abrasive resistant liner. The headers in the high temperature region are fabricated from Hastelloy material. To maintain the integrity of all pipe penetrations into the vessels, Hastelloy sleeves were placed integral to the concrete walls.

\section{Outlet Ductwork and Flues}

The flue gas outlet from the scrubber module is an historically maintenance intensive area. This is an important area in which maintenance can be reduced. Existing wet scrubbers have long runs of outlet duct to the chimney as well as exit dampers. The maintenance in this area has been extensive with the repairs having to be done in accordance with exacting standards in less than ideal positions and conditions. This usually results in more maintenance. Typical materials used in the construction of the duct and dampers are high alloy metals which are expensive and difficult to repair.

The second major feature of the Milliken DOE demonstration project is the direct exhaust of the flue gas from the absorber module to the flue. Each module exhausts through a dedicated FRP flue. The flues are located directly above the absorbers. As previously mentioned, the Milliken scrubber is a single module design. Therefore, by tying the exhaust from the two 
modules together in a common flue, outlet dampers and interconnecting ductwork were eliminated.

The Milliken design has a transition from the rectangular module to the round flue. Material for the transition is carbon steel with a flake glass lining. A catch tray was added to the transition to protect the mist eliminators from any gypsum which might build up on the flue and fall. The catch tray also provides a good work point to inspect the flake glass coating and stack drain system.

\section{Pumps and Piping}

All process pumps were constructed with rubber lined casings. Due to the project objective of demonstrating zero wastewater discharge, Hastelloy shafts with mechanical seals were utilized on all pumps. The impellers on the absorber recycle pumps, supplied by Georgia Iron Works, are made of a proprietary high nickel alloy. The impellers on all other process pumps are rubber lined.

The use of fiberglass pipe on the project was reviewed carefully and maintenance considerations played a key role in that decision. Two important maintenance considerations that were key to the use of fiberglass were the life expectancy and the ease with which the pipe could be changed or repaired. Based upon the available data from the manufacturer, the life expectancy of the fiberglass pipe in slurry service was compared to rubber lined pipe. The ease with which the pipe could be worked was reviewed, taking into account the ability to cut it apart and reconfigure, to add in spools and the lower weight to handle the pipe. There are two types of fiberglass used: one has an internal abrasion resistant liner, and the other is unlined. Rubber lined pipe was only used in the limestone grinding circuit and the limestone addition to the absorber module.

\section{Tanks and Agitators}

The process tanks were all constructed of plain carbon steel and coated with either flake glass or rubber. The tanks that contained the most abrasive materials were coated with rubber.

Flake glass lining was utilized on all other tanks. The agitators on the absorber modules were constructed with Hastelloy wetted parts including mechanical seals. All process tank agitators were top mounted and constructed of rubber lined wetted parts.

\section{Valves}

All isolation valves in process slurry lines are Clarkson knife-gates with Hastelloy gates and rubber liners. To minimize the amount of slurry spillage in the vicinity of the valves, a valve drain system was designed and installed. The valve drains are routed to the nearest process trench or drain line. Throttle valves installed in process slurry lines are rubber lined Clarkson concentric reducing valves. Isolation valves in the flush system, which has a minimal solids 
loading, are Saunders rubber lined diaphragm valves. The butterfly valves used for the mist eliminator wash system are Amri wafer valves with rubber lined bodies and alloy disks.

\section{Centrifuges}

Final gypsum dewatering is completed in vertical basket centrifuges supplied by KraussMaffei. Vacuum belts were considered for use during the design phase, but centrifuges offered better dewatering characteristics and lower maintenance requirements. The centrifuges are rubber lined with Hastelloy feed nozzles, wash pipes and scraper blades.

\section{Hydroclones}

Primary and secondary dewatering is completed in hydroclones supplied by Warman. All wetted parts are rubber lined. Due to the testing requirements, the primary hydroclone feed boxes were split in two in order to facilitate isolation of one unit during testing. The original clone apexes and vortexes were made of rubber with ceramic pieces to be supplied after on site sizing was completed.

\section{Maintenance Performance of the Design}

It is a lofty goal to design a system with emphasis on the maintainability, it is quite another to evaluate the results. Milliken station Unit 2 has been operating since January 1995 and Unit 1 has been in service since June 1995. The Milliken project has had its successes and a few setbacks.

As a part of a separate study being performed to determine the maintainability of a tile lined module, we have installed a test module at another operating FGD facility. The test module receives a slip stream of absorber slurry to simulate operating conditions and has been in service for two years. By intentionally damaging the interior of the test module, three repair procedures have been tested and proven reliable at the Stebbins tile lined NYSEG test module.

The three conditions tested include cracks in grout, cracks in tiles and holes penetrating the module wall. A chemically resistant epoxy based grout can be used to repoint areas that have cracked or where existing grout has eroded. Complete tiles can be replaced by chipping out the old tile, removing two inches of concrete behind the tile, resurfacing with a Portland cement, cementing the new tile in place, and regrouting with a chemically resistant grout mixture. To repair holes on-line, holes are drilled around the leaking area in a random fashion, the new holes are fitted with special Zerk type grease fittings, finally a grease gun is used to pump water and then a chemical grout foam into the new holes.

\section{Absorber Modules}


The Stebbins tile on both modules is performing well. We have not seen any signs of abrasion on the tiles. During startup, cracks had developed on both modules that "selfhealed" within a week. Three cracks on interior walls that did not progress through the module wall were repaired on the Unit 1 module. The cracks were through the center of adjoining tiles. The repair was accomplished by grinding the crack and filling with an epoxy based mortar.

The access that was designed into the modules has proved to be extremely beneficial. The Unit 2 module has been down several times to review the internals. The access at each spray level has provided easy inspection of the spray headers. When the need to change or clean a nozzle is required, entry with aluminum picks positioned on the various beams allows for a safe work platform. The large access door at the base of the modules has provided an easy route for the cleanup of leftover solids in the module. This door also has allowed the use of electric man lifts to inspect upper sump levels and the turning vanes.

The biggest problem observed in the modules to date is with the rubber on the turning vanes. Due to the combined cocurrent/countercurrent absorber module, a large set of rubber coated turning vanes is installed at the bottom of the countercurrent section. The rubber is installed as two layers of $1 / 4$ in. sheets. Some of the outer layer has been pealing off, causing pluggage of recycle spray nozzles. Due to the resulting flow restriction in the nozzle, scale has formed below the nozzle. Eventually the nozzle may become completely plugged and break. We have repaired the rubber on the turning vanes in both modules by using the large doors in the bottom of the module to allow access with an electric lift.

A problem with broken nozzles has also been experienced. The recycle spray nozzles are flange mounted, pig-tail style and made of a ceramic material which is very brittle. We are currently experimenting with stainless steel and stellite nozzles.

The mist eliminators have been performing well. Reducing the frequency of washing the top of the fine mist eliminator caused some pluggage early on Unit 2. The plugged areas were power washed to remove the build-up. The problem has not been repeated since the mist eliminator wash frequency was re-adjusted.

\section{Outlet Ductwork and Flues}

Having the flues over the modules has proved a good decision. The only need for maintenance in this area was for the removal and recoating of lifting lugs left in the transition section with the thought that they would aid in the inspection and maintenance of this area. The catch tray provides a good platform from which to inspect the integrity of the coating. Access to the transition section is good through the door provided. A portable work platform which is constructed on the catch tray provides access to the expansion joint for inspection.

\section{Pumps and Piping}


All pump linings are performing well. We have replaced some liners on the slurry bleed pumps due to erosion in the impeller clearance area. This appears to have been caused by foreign material being trapped in the pump. The mechanical seals are performing well with the exception of the small pumps. We have seen approximately four seals fail due to foreign objects getting caught in the seal area.

Fiberglass piping is holding up well in all areas of service. We have experienced one area on the centrifuge feed loop that has excessive erosion downstream from a throttling valve. The piping will be re-configured to eliminate the cause of the erosion. During construction there were times when the fabrications required modifications. The pipe was cut apart, refitted, glued and is now providing excellent service. As part of the DOE demonstration the need for additional test ports have been required and the ability to install these ports wherever required is easy. The abrasion resistant lining in the heavier slurry lines is showing no signs of wear. The same can be said of the spray headers with no wear shown on the outside from spray impingement or the inside.

The rubber lined piping in the system has also shown no sign of wear.

\section{Tanks and Agitators}

All rubber lined tanks are performing well. We have experienced two failures on nozzle areas of the flake glass lined tanks. The failures appear to have been caused by a poor lining application. The module $\mathrm{pH}$ monitor was originally mounted in a flake glass lined vessel, which also experienced nozzle failures. The internal of the vessel was apparently too intricate to use flake glass lining. The $\mathrm{pH}$ tank was replaced with a PVC inverted u-tube and orifice plate.

\section{Miscellaneous Equipment}

The primary and secondary hydroclones were installed with rubber apexes and vortexes to facilitate field sizing. As expected, the rubber showed signs of abrasion particularly in the primary hydroclone apex. We have since installed ceramic pieces. All other process related equipment including ball mills, centrifuges, oxidation blowers and valves are performing well.

\section{Summary and Conclusions}

The Milliken scrubber has been designed by applying lessons learned from existing FGD systems regarding material selection, equipment lay-out, access provisions and resulting maintenance impacts. It is too early in the life of the Milliken Station FGD to state the complete effectiveness of the design related to the maintainability of the system. However, after 17 months of operation, the expected benefits of many of the design features have already been demonstrated. The Stebbins tile lined module has been virtually maintenance free. The transition area between the modules and flues has shown no evidence of failure. 
The access points and maintenance provisions in the module have been used to reduce inspection set-up time. 